\title{
Use of nanoparticle binders for paper coatings: A review
}

\begin{abstract}
Starch is a biopolymer that is used as a co-binder alongside synthetic petroleum based latex binders for paper coating applications, though it causes production downtimes due to the problems during cooking process, such as gelling; lack of full expansion of starch granules; increase in viscosity during cooling; bacteria growth in cooked starch and difficulties in viscosity control during storage. On the other hand, synthetic binders negatively affect paper recyclability and biodegradability. To overcome these problems, a new biopolymer binder has been introduced to the paper manufacturing, being used initially as a partial replacement for petroleum based synthetic latex polymers. This study reviews the recent developments of nanoparticle biopolymer binders, referred to as biolatex binders. These binders are shipped dry and can be dispersed in water without cooking requirement while improving paper quality and reducing costs of paper manufacturing. They also provide quality benefits, coater runnability improvements and new higher solids coating formulations for future product advancements.
\end{abstract}

\section{KEY WORDS}

Binder, paper coating, biopolymer, starch, nanoparticle

\author{
Bilge Nazli Altay ${ }^{1}$, \\ Steven Bloembergen², \\ Cem Aydemir ${ }^{3}$, \\ Arif Karademir ${ }^{4}$, \\ Paul D. Fleming 5 \\ ${ }^{1}$ Marmara University, Institute of \\ Pure and Applied Sciences, Printing \\ Technologies, Istanbul, Turkey \\ ${ }^{2}$ Ecosynthetix Corporation, \\ Ontaria, Canada \\ ${ }^{3}$ Marmara University, School of \\ Applied Sciences, Department of \\ Printing Technologies, Istanbul, \\ Turkey \\ ${ }^{4}$ Bursa Technical University, Faculty \\ of Forestry, Forestry Industry \\ Engineering, Division of Pulp and \\ Paper, Bursa, Turkey \\ ${ }^{5}$ Western Michigan University, \\ Chemical and Paper Engineering, \\ Kalamazoo, Michigan, USA \\ Corresponding author: \\ Bilge Nazli Altay \\ e-mail: \\ bilgenazli@gmail.com
}

First recieved: 10.03.2017.

Accepted: 11.05.2017.

\section{Introduction}

The growing interest by many industrial segments to use sustainable materials has stimulated the development of new biopolymer materials. Some of the biomaterials that have a use in papermaking and coating industry are cellulose, coating starches (modified low molecular weight grades of the native material), chitosan, soy protein, alginate, casein, zein, lecithin and cellulose derivatives such as methyl cellulose and carboxymethyl cellulose (CMC), among others (Klass, 2011). Paper grades sometimes need to be coated with these materials to improve paper printability, surface characteristics or to add extra functional properties.
Printability is the main quality for high quality colour reproduction, increased ink gloss, uniform appearance or preventing print defects. It is greatly affected by paper porosity since the rate and depth of ink receptivity depends on it. Porosity is measured by the number and size of the voids within the coating layer. The voids can be controlled with different pigments, binder types, dispersing agents and additives in the coating layer.

Nanoparticles (within the range of 1 and $100 \mathrm{~nm}$ ) show different properties compared to their bulk materials. Some of the recent nanomaterials in the papermaking and coating industry include nano crystalline cellulose (NCC) (Klass, 2007; Zaman et al., 2012; Cha et al., 2014), 
nano fibrillated cellulose (NFC) (Martins et al., 2013; Missoum et al., 2013; Liu et al., 2015), TEMPO-oxidized cellulose nano fibrils (TONC) (Fujisawa et al., 2011; Fukuzumi, 2011; Okita et al., 2011; Fukuzumi, Saito \& Isogai, 2013; ) and nanoparticle biopolymer binders (Giezen et al., 2004; Helbling et al., 2004; Van Soest et al., 2004; Bloembergen, Kappen \& Beelen, 2005; Helbling et al., 2007a; Helbling et al., 2007b; Figliolino \& Rosso, 2009; Lee, Bloembergen \& Van Leeuwen, 2010; Oberndorfer, Greenall \& Bloembergen, 2011; Houze \& Pajari, 2012; Shin et al., 2012; Shin et al., 2013). The studies have demonstrated that these nano materials improve various important properties of coated paper. Figure 1 represents an example for the tensile strength and elastic modulus differences between the paper, polyvinyl alcohol (PVA) film, cellophane and TOCN film.

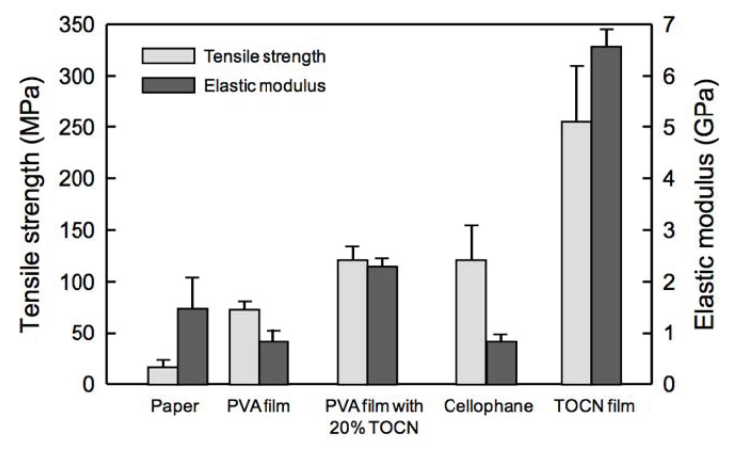

» Figure 1: Mechanical properties of TOCN films (Fukuzumi, 2011)

Synthetic polymers, such as styrene butadiene (SB), polyvinyl acetate and styrene acrylics, are petroleum based latex binders, therefore they are not environmentally benign and suffer from price instability with major up and down swings linked to oil prices. They have been used in paper coating applications due to their ability of increasing paper properties and mechanical strength though they reduce recyclability and can cause "white pitch" issues with deposits on calender rolls, etc. Biopolymers have an advantage of being sustainable, renewable and biodegradable, therefore they also reduce the carbon footprint. Biopolymer materials have relatively stable pricing and these advantages are driving adoption of these natural products.

When cooked, starch is a mostly soluble biopolymer produced from plant sources such as corn (maize), potato, wheat, tapioca (cassava), pea, rice. It has been used in paper coating applications as a co-binder (Klass, 2011). Conventionally, starch is purchased in dry granular powder form, either in modified (acid thinned, thermally modified, thinned/hydroxyethylated, etc.) or in its unmodified (native) form, and then cooked or chemically/enzymatically modified on site at the mill before it is used in the paper coating (Klass, 2007). Natural (unmodified, pearl, native) starch is attractive due to its low price, but poor process control frequently reduces productivity and paper quality (Mishra, 2005). Starch in its native form is an ultra-high molecular weight (MW) polymer (>300 million $\mathrm{g} /$ mole or Daltons) and that becomes a challenge during cooking production. When starch is cooked in solutions (to allow it to act as a binder) MW must be sharply reduced, to yield cooked solutions with sufficient substance (i.e. \% solids). Modified starch usage is more common than natural starch due to added functionalities in paper industry. The typical cooking procedure is that starch must be well agitated at room temperature, then heated up to 90-95 $\mathrm{C}$ and held at that temperature for 20-30 minutes while maintaining good agitation for complete cook-out of the starch. Improper cooking for paper coating may cause gelling (lack of full expansion of starch granules); increase in viscosity during cooling; bacterial growth in cooked starch or difficulties in viscosity control during storage, all of which can cause quality issues and production downtimes. For papermaking, if starch granules are not ruptured completely, the size press nip will likely reject it, and later may cause viscosity changes, drying and scale problems on the paper machine.

The first starch nanoparticle biopolymer binder in the paper industry were developed, produced and commercialized by EcoSynthetix Corporation as EcoSphere ${ }^{\mathrm{TM}}$ biolatex ${ }^{\mathrm{TM}}$ binders with the intention of replacing petroleum-based synthetic latex (Bloembergen et al., 2011). EcoSynthetix has $>100,000$ ton/annum capacity at its manufacturing facilities in North America and Europe (Van Ballegooie et al., 2012; Van Ballegooie et al., 2013) and the biolatex has $99 \%$ bio based agricultural feedstock that makes it sustainable, renewable and biodegradable. These advantages also help companies reduce their carbon footprint. EcoSynthetix has patented the process of using a twin-screw extruder with different shear forces, upstream pressure and a crosslinking agent to generate starch nanoparticles around $100 \mathrm{~nm}$ (dominant size range is 20-150 nm, ideal for low viscosity biolatex dispersions). Figure 2 represent the conversion of native starch to the biolatex emulsion polymer along with TEM, STEM and SEM images of the native starch granules and biolatex particles. Unlike natural (native) and modified starch, these nanoparticles do not require cooking, and can be readily dispersed in water due to their internally crosslinked, water-swollen and deformable colloid particle nature (Bloembergen et al., 2010; Wildi, Van Egdom \& Bloembergen, 2015). It is reported that starch is known as a stiff and brittle polymer while the nanoparticle biopolymer is more flexible and helps to reduce folding and scoring cracks (Klass, 2007). The extrusion process is used to bring down the starch granule diameters from micron to nano range. In Figure 3, the comparison of particle sizes between the biopolymer nanoparticles binders and synthetic/natural binders are represented. Over the past two decades, SB latex has become the dominant paper coating binder system in the industry. Its particle size has 


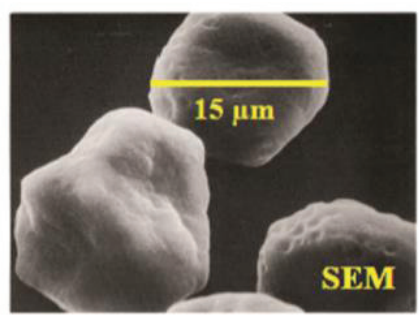

Native Starch Granules

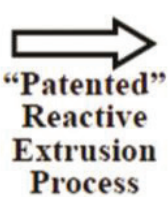

Process
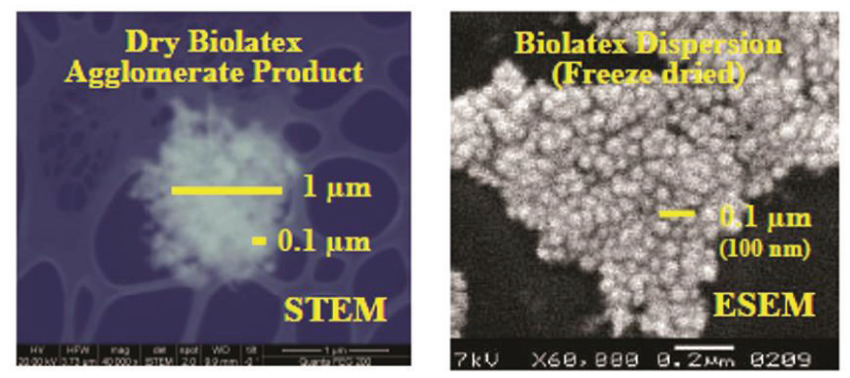

„ Figure 2: Native starch conversion to biolatex (Klass, 2011)

been pushed to smaller particle sizes towards an aggressive $100-120 \mathrm{~nm}$ target, given that smaller latex particle sizes have higher surface area, beneficial for binding performance. Biolatex emulsions do not require surfactants nor other repulsion mechanisms that help keep synthetic latex particles in stable suspensions (which inadvertently adds cost and reduces other performance requirements). The biolatex binders, on the other hand, are smaller in size, which is beneficial to binding power, and they do not contain added surfactants but produce naturally highly stable dispersions with long shelf lives.

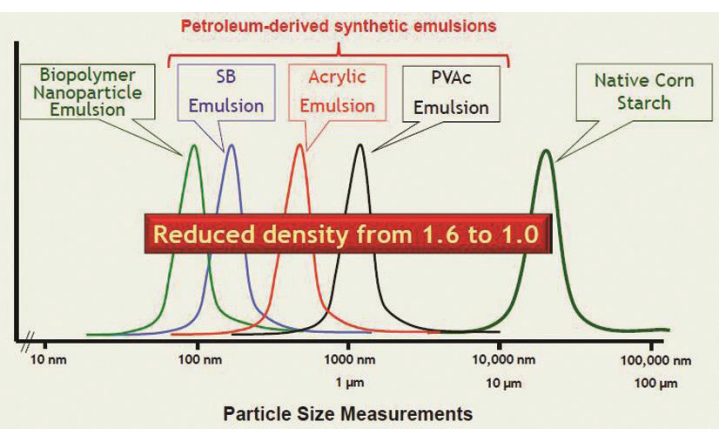

» Figure 3: Particle size comparison of binders (Bloembergen, 2009)

\section{Materials and Methods}

Assessment method for this study was a literature review. Existing knowledge gathered based on the data from patents, journals, conference papers, industry magazines and pilot testing. In pilot test experiments, the coating formulation ingredients were clay, ground calcium carbonate (GCC), titanium dioxide $\left(\mathrm{TiO}_{2}\right)$, carboxymethyl cellulose (CMC), lubricant, rheology modifier and optical brightening agent (OBA). Synthetic latexes in coating formulations were replaced on a 1:1 basis with the EcoSphere bio based nanoparticle latex.

\section{Results and Discussions}

According to ASTM D6866 bio based content testing, the biolatex binder has 99+\% bio based agricultural feedstock, while synthetic latex is based on $99+\%$ fossil. The test indicated that the biolatex binder is a sustainable, recyclable and biodegradable binder (Figliolino \& Rosso, 2009; Lee, Bloembergen \& Van Leeuwen, 2010; Oberndorfer, Greenall \& Bloembergen, 2011; Houze \& Pajari, 2012; Shin et al., 2012; Shin et al., 2013). The research showed that $73 \%$ carbon footprint reduction is possible with biolatex binder (Lee, Bloembergen \& Van Leeuwen, 2010). Overall results conducted by the researchers showed that 30 to $50 \%$ of synthetic latex replacement with biolatex binder is immediately possible in coating formulation. Further optimization can help attain higher substitution levels, coating structure, strength and optical properties were improved. The biolatex binder showed increase in brightness; equal or higher gloss and better opacity values. Brightness value would be increased further when the $\mathrm{TiO}_{2}$ pigment co-extruded with the binder (Lee, Bloembergen \& Van Leeuwen, 2010). The biolatex binder could increase solid content 1 to $3 \%$ that enables saving in dryer energy due to having less water content in the coating structure (Figliolino \& Rosso, 2009; Oberndorfer, Greenall \& Bloembergen, 2011; Houze \& Pajari, 2012; Shin et al., 2012; Shin et al., 2013). The amount of some coating components such as CMC, polyvinyl alcohol and rheology modifier were eliminated or decreased with the biolatex binder addition (Figliolino \& Rosso, 2009; Oberndorfer, Greenall \& Bloembergen, 2011; Shin et al., 2013; ). Runnability of the coating in the coater was increased due to better coating uniformity, better rheology and superior water retention that has been achieved by using biolatex (Oberndorfer, Greenall \& Bloembergen, 2011; Shin et al., 2013). Better paper stiffness value was also reported (Oberndorfer, Greenall \& Bloembergen, 2011). The experiment showed no significant effect on wet pick performance of the coating with biolatex binder, yet the IGT dry pick performance improved 7 to $31 \%$. Lower binder migration was observed when $20 \%$ of synthetic binder replaced with biolatex binder (Figliolino \& Rosso, 2009).

\section{Conclusion}

Bio based nanoparticle latex binders are successfully replacing petroleum based synthetic binders while improving paper quality. The crosslinked, water-swollen and deformable colloid particles are represented that 
they can enable further cost savings for manufacturers since the biolatex binder does not require the typical starch cooking procedure and can be readily dispersed directly in water. Biolatex binder has $99+\%$ bio based agricultural feedstock. It is sustainable, renewable and biodegradable and helps paper manufacturers to reduce their carbon footprint. Future studies need to investigate optical, mechanical and printability properties of different papers coated with bio based nanoparticle binder.

\section{Acknowledgements}

This study was supported in part by the Scientific and Technological Research Council of Turkey (TUBITAK) under the 2214-A program.

\section{References}

Bloembergen, S. (2009) Nanoparticle biopolymer latexes based on agro materials with a very low carbon footprint use in a variety of specialty paper and paperboard grades. In: Technical Association of the Pulp and Paper Industry. 2009 Specialty Papers Conference Proceedings, 4-5 November 2009, Chicago, USA. Norcross, TAPPI Press, pp. 439-449.

Bloembergen, S., Kappen, F. \& Beelen, B. (2005) Environmentally friendly biopolymer adhesives and applications based thereon. US6921430 B2 (Patent).

Bloembergen, S., McLennan, I. J., Van Leeuwen, J. \& Lee, D. I. (2010) Specialty biobased monomers and emulsion polymers derived from starch. In: Technical Association of the Pulp and Paper Industry. TAPPI 11th Advanced Coating Fundamentals Symposium: The Latest Advances in Coating Research and Development Proceedings, 11-13 October 2010, Munich, Germany. Norcross, TAPPI Press. pp. 17-35.

Bloembergen, S., Vanegdom, E., Wildi, R., McLennan, I. J., Lee, D. I., Klass, C. P. \& Van Leeuwen, J. (2010) Biolatex Binders for Paper and Paperboard Applications. Journal of Pulp and Paper Science. 36 (3), 151-161.

Cha, R., Wang, C., Cheng, S., He, Z. \& Jiang, X. (2014) Using carboxylated nanocrystalline cellulose as an additive in cellulosic paper and poly (vinyl alcohol) fiber paper. Carbohydrate Polymers. 110, 298-301. Available from: doi: 10.1016/j.carbpol.2014.04.003 [Accessed 12th April 2016].

Figliolino, F. C. \& Rosso, F. (2009) Reducing Carbon Footprint with Biolatex. Paper $360^{\circ}$ Magazine. 4 (6), 25-28.

Figliolino, F. C., Rosso, F., Van Leeuwen, J. \& Klass, C. P. (2009) Mill experiences with biolatex in Brazil. In: Technical Association of the Pulp and Paper Industry. TAPPI PAPERCON 09: PAPERCON '09 Conference Proceedings, May 31-03 June 2009, St. Luis, USA. Norcross, TAPPI Press. Section 19-1.

Fujisawa, S., Okita, Y., Fukuzumi, H., Saito, T. \& Isogai, A. (2011) Preparation and characterization of
TEMPO-oxidized cellulose nanofibril films with free carboxyl groups. Carbohydrate Polymers. 84 (1), 579-583. Available from: doi: 10.1016/j.carbpol.2010.12.029 [Accessed 28th April 2016].

Fukuzumi, H. (2011) Studies on Structures and Properties of TEMPO-oxidized Cellulose Nanofibrils Films. PhD thesis. University of Tokyo.

Fukuzumi, H., Saito, T. \& Isogai, A. (2013) Influence of TEMPO-oxidized cellulose nanofibril length on film properties. Carbohydrate Polymers. 93 (1), 172-177. Available from: doi: 10.1016/j.carbpol.2012.04.069 [Accessed 28th April 2016].

Giezen, F. E., Jongboom, R. O. J., Feil, H., Gotlieb, K. F. \& Boersma, A. (2004) Biopolymer Nanoparticles. US6677386 B1 (Patent).

Helbling, A. M., Hills, M. R., Stollmaier, F. T. \& Annen, T. M. S. (2004) Use of starch dispersions as binder in coating compositions and process for preparing the starch dispersions. US6825252 B2 (Patent).

Helbling, A. M., Hills, M. R., Stollmaier, F. T. \& Annen, T. M. S. (2007a) Use of starch dispersions as binder in coating compositions and process for preparing the starch dispersion. US7285586 B2 (Patent).

Helbling, A. M., Hills, M. R., Stollmaier, F. T. \& Annen, T. M. S. (2007b) Use of starch dispersions of crosslinked cationic starch in papermaking. US7160420 B2 (Patent).

Houze, R. \& Pajari, T. (2012) Biopolymers in Papermaking. Paper $360^{\circ}$ Magazine. 56-57. Available from: http://www.roquette-polymeresnaturelsindustriels.fr/media/deliacms/media//75/758383e1a6.pdf [Accessed 22th April 2016].

Klass, C. (2007) New Nanoparticle Latex offers Natural Advantage. Paper $360^{\circ}$ Magazine. 30-31.

Klass, C. (2011) Biobased Materials for Paper Coating. In: Technical Association of the Pulp and Paper Industry. PAPERCON 2011: PAPERCON 2011 Conference Processdings, 1-4 May, Covington, USA. Norcross, TAPPI Press. pp. 2249-2081.

Lee, D. I., Bloembergen, S. \& Van Leeuwen, J. (2010) Development of New Biobased Emulsion Binders. In: Technical Association of the Pulp and Paper Industry. PAPERCON 2010: PAPERCON 2010 Conference Processdings, 2-5 May Atlanta, USA. Norcross, TAPPI Press.

Liu, K., Chen, L., Huang, L., Ni, Y. \& Sun, B. (2015) Enhancing antibacterium and strength of cellulosic paper by coating triclosan-loaded nanofibrillated cellulose (NFC). Carbohydrate Polymers. 117, 996-1001. Available from: doi: 10.1016/j. carbpol.2014.10.014 [Accessed 22th April 2016].

Martins, N. C. T., Freire, C. S. R., Neto, C. P., Silvestre, A. J. D., Causio, J., Baldi, G., Sadocco, P. \& Trindade, T. (2013) Antibacterial paper based on composite coatings of nanofibrillated cellulose and ZnO. Colloids and Surfaces A: Physicochemical and Engineering Aspects. 417, 111-119. Available from: doi: 10.1016/j. colsurfa.2012.10.042 [Accessed 22th April 2016]. 
Mishra, A. K. (2005) What You Need to Know About Starch in Papermaking, Solutions!. Process and Paper. 88 (8), 40-42.

Missoum, K., Martoïa, F., Belgacem, M. N. \& Bras, J. (2013) Effect of chemically modified nanofibrillated cellulose addition on the properties of fiber-based materials. Industrial Crops and Products. 48, 98-105. Available from: doi: 10.1016/j. indcrop.2013.04.013 [Accessed 22th April 2016].

Oberndorfer, J., Greenall, P. \& Bloembergen, S. (2011) Coating and Print Performance of Biobased Latex in European Graphic Papers. In: Technical Association of the Pulp and Paper Industry. PAPERCON 2011: PAPERCON 2011 Conference Processdings, 1-4 May, Covington, USA. Norcross, TAPPI Press. pp. 2180-2195.

Okita, Y., Fujisawa, S., Saito, T. \& Isogai, A. (2011) TEMPO-Oxidized Cellulose Nanofibrils Dispersed in Organic Solvents. Biomacromolecules. 12 (2), 518-522. Available from: doi: 10.1021/ bm101255x [Accessed 22th April 2016].

Shin, J. Y., Jones, N., Fleming, P. D., Joyce, M. K., Lee, D. I., DeJong, R. \& Bloembergen, S. (2013) Dynamic Water Retention Properties of Biobased Latex Containing Coating Colors. In: Technical Association of the Pulp and Paper Industry. PAPERCON 2013: PAPERCON 2013 Conference Processdings, 27 April -1 May, Atlanata, USA. Norcross, TAPPI Press. pp. 150-169.

Shin, J. Y., Jones, N., Lee, D. I., Fleming, P. D., Joyce, M. K., DeJong, R. \& Bloembergen, S. (2012) Rheological Properties of Starch Latex Dispersions and Starch Latex-Containing Coating Colors. In: Technical Association of the Pulp and Paper Industry. PAPERCON 2012: Growing the Future - Co-located with Control Systems 2012, PAPERCON 2012 Conference Proceedings, New Orleans, USA, 22-25 April. Norcross, TAPPI Press. pp. 382-406.
Song, D., Thio, Y. S. \& Deng, Y. (2011) Starch nanoparticle formation via reactive extrusion and related mechanism study. Carbohydrate Polymers. 85 (1), 208-214. Available from: doi: 10.1016/j.carbpol.2011.02.016 [Accessed 22th April 2016].

Van Ballegooie, P., Bloembergen, S., Greenall, P. \& DeJong, R. (2013) EcoSynthetix' three pillar approach: Delivering economic feasibility - high performance - sustainability advantages. World Pulp \& Paper. 88-92. Available from: https:// static1.squarespace.com/static/568969badf40f3987cccc1d9/t/568d4e21c21b86066af98d8b/1452101153659/88-92ECOSYNTHETIX_ WP\%26P_2013.pdf [Accessed 22th April 2016].

Van Ballegooie, P., Greenall, P., Bloembergen, S. \& DeJong, R. (2012) EcoSphere ${ }^{\circledR}$ biolate ${ }^{\circledast}$ binders: Next generation solutions for today's paper coating industry. World Pulp \& Paper. 100.

Van Soest, J. J. G., Stappers, F. H. M., Van Schijndel, R. J. G., Gotlieb, K. F. \& Feil, H. (2004) Method for the preparation of starch particles. US6755915 B1 (Patent).

Wildi, R. H., Van Egdom, E. \& Bloembergen, S. (2015) Process for producing biopolymer nanoparticles. US9011741 B2 (Patent).

Zaman, M., Xiao, H., Chibante, F. \& Ni, Y. (2012) Synthesis and characterization of cationically modified nanocrystalline cellulose. Carbohydrate Polymers. 89 (1), 163-170. Available from: doi: 10.1016/j. carbpol.2012.02.066 [Accessed 22th April 2016].

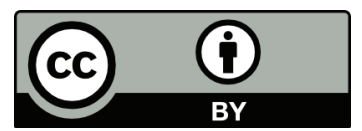

(C) 2017 Authors. Published by the University of Novi Sad, Faculty of Technical Sciences, Department of Graphic Engineering and Design. This article is an open access article distributed under the terms and conditions of the Creative Commons Attribution license 3.0 Serbia (http://creativecommons.org/licenses/by/3.0/rs/). 